\title{
JOGOS DE TABULEIRO: RECURSO LÚDICO NA APRENDIZAGEM DE CRIANÇAS EM SITUAÇÃO DE VULNERABILIDADE
}

\author{
JUEGOS DE MESA: RECURSOS LÚDICOS PARA EL APRENDIZAJE DE LOS NIÑOS \\ EN SITUACIÓN DE VULNERABILIDAD
}

\author{
BOARD GAMES: PLAYFUL RESOURCE FOR LEARNING OF CHILDREN IN \\ VULNERABILITY SITUATION
}

\author{
Talita Silva Perussi VASCONCELLOS ${ }^{1}$ \\ Rosimeire Maria ORLANDO ${ }^{2}$
}

\begin{abstract}
RESUMO: Este artigo é um recorte de uma dissertação de mestrado, realizada no Programa de Pós-graduação em Educação Especial da Universidade Federal de São Carlos. Teve como objetivo geral observar e analisar o uso do jogo de tabuleiro no processo de apropriação de habilidades relacionadas à leitura e escrita de crianças em situação de vulnerabilidade social. A presente pesquisa se realizou em uma Organização da Sociedade Civil do interior do estado de São Paulo. Foram participantes deste estudo quatorze meninas de sete a dez anos de idade que frequentavam a referida organização. A pesquisa de abordagem qualitativa, caracterizada como pesquisa participante, se valeu dos procedimentos de observação, entrevista e avaliação pedagógica. Contou com três etapas: 1. Sondagem inicial; 2. Intervenção com jogos de tabuleiro; 3. Finalização. Os resultados mostraram um ganho de habilidades ao processo de aquisição de leitura e escrita, visto que a aplicação das avaliações demonstrou que todas as meninas ganharam habilidades de escrita novas possivelmente por influência do jogo.
\end{abstract}

PALAVRAS-CHAVE: Jogos de tabuleiro. Aprendizagem. Vulnerabilidade social.

RESUMEN: Este artículo es un extracto de una tesis de maestría, realizada en el Programa de Posgrado en Educación Especial de la Universidad Federal de São Carlos. El objetivo general era observar y analizar el uso del juego de mesa en el proceso de apropiación de habilidades relacionadas con la lectura y escritura de niños en situaciones de vulnerabilidad social. Esta investigación se llevó a cabo en una organización de la sociedad civil, en el interior del estado de São Paulo. Catorce niñas de siete a diez años que asistieron a esta organización participaron en este estudio. La investigación cualitativa, caracterizada como investigación participativa, utilizó procedimientos de observación, entrevista y evaluación pedagógica. Tenía tres etapas: 1. Encuesta inicial; 2. Intervención con juegos de mesa; 3. Terminación. Los resultados mostraron un aumento en las habilidades durante el proceso de adquisición de lectura y escritura, ya que la aplicación de las evaluaciones demostró que

1 Universidade Estadual Paulista (UNESP), Araraquara - SP - Brasil. Doutoranda no Programa de PósGraduação em Educação Escolar. ORCID: https://orcid.org/0000-0003-4955-5974. E-mail: tallita.perussi@gmail.com

${ }^{2}$ Universidade Federal de São Carlos (UFSCAR), São Carlos - SP - Brasil. Professora do Departamento de Psicologia. Doutorado em Educação Escolar (UNESP). ORCID: https://orcid.org/0000-0002-0990-6146.E-mail: meire_orlando@ufscar.br

RIAEE - Revista Ibero-Americana de Estudos em Educação, Araraquara, v. 16, n. 4, p. 2630-2647, out./dez. 2021. e-ISSN: 1982-5587 
todas las niñas desarrollaron nuevas habilidades posiblemente debido a la influencia del juego.

PALABRAS CLAVE: Juegos de mesa. Aprendizaje. Vulnerabilidad.

ABSTRACT: This article is an excerpt from a master's dissertation, carried out in the Postgraduate Program in Special Education at the Federal University of São Carlos. The general objective was to observe and analyze the use of the boardgame in the process of appropriating skills related to reading and writing of children in situations of social vulnerability. This research was carried out in a Civil Society Organization, in the interior of the state of São Paulo. Fourteen girls from seven to ten years old who attended this organization participated in this study. It had three stages: 1. Initial survey; 2. Intervention with board games; 3. Completion. The results showed a gain in skills during the process of acquisition of Reading and writing, since the application of the evaluations demonstrated that all girls developed new skills possibly due to the influence of the game..

KEYWORDS: Bordgames. Resource. Vulnerability.

\section{Introdução}

Partindo do pressuposto de que o meio influencia o desenvolvimento e a aprendizagem, não se pode negar a relação entre o desenvolvimento humano e o ambiente, sendo que a criança e o ambiente se influenciam mutuamente (RAPOPORT, 2009). Logo, crianças que se desenvolvem em ambientes desfavoráveis, que presenciam e sofrem práticas violentas em família e com pouco estímulo por parte dos pais tendem a ter o seu desenvolvimento prejudicado e a ser influenciadas pelas mediações negativas que o meio no qual estão inseridas lhes submetem (SILVA, 2009).

No que se refere à aprendizagem, sabe-se que se inicia antes mesmo do ingresso da criança na escola, sendo que aprendizagem e desenvolvimento estariam interligados (RAPOPORT, 2009); ressalta-se que apenas se mostra efetiva com um processo de mediação eficaz, compreendendo-a como a relação do homem com o mundo e com outros homens, desenvolvendo com tal processo as funções psicológicas superiores (VIGOTSKI, 1998).

Considerando que a aprendizagem se dá por meio da mediação com o outro, destacase a importância de estar em um ambiente em que a aprendizagem seja favorecida, tendo como ponte para tal adultos capazes e dispostos a estimular o potencial destas crianças (SILVA, 2009).

Em comunidades vulneráveis, pouquíssimas famílias têm a possibilidade de dispor de materiais, jogos, livros ou mesmo de tempo e atenção para se dedicarem às crianças. É 
inegável considerar que as vivências destas crianças possam afetar de alguma forma sua vida escolar (VIGOTSKI, 1998).

De acordo com Ferreira e Marturano (2002),

As crianças provenientes de famílias que vivem com dificuldades econômicas e habitam em comunidades vulneráveis, tendem a apresentar mais problemas de desempenho escolar e de comportamento (FERREIRA; MARTURANO, 2002, p. 39).

O fato de muitas crianças estarem distantes de formas de estimulação intelectual, que poderiam lhes despertar interesse e curiosidade, pode acarretar altas taxas de problemas e de fracasso escolar, principalmente em bairros pobres (BEE, 1997).

No mesmo sentido, Santos e Marturano (1999) apontam que as dificuldades de aprendizagem escolar estão na maioria dos casos relacionadas ao déficit em habilidades sociais, problemas emocionais e/ou de comportamento. Enquanto estes fatores estiverem fortemente associados aos fatores de risco no ambiente escolar e social, podem afetar negativamente o desenvolvimento. O desempenho escolar de uma criança é certamente resultado de seu desenvolvimento e das condições vividas durante tal período (SILVA, 2009). De acordo com Bee (1997, p. 306),

[...] não é o estresse vivido pela família, mas a capacidade da família para enfrentar os estresses de suas vidas para criar um ambiente suficientemente apoiador para que a criança desenvolva as necessárias competências intelectuais e sociais.

Ressalta-se que vivemos em mundo orientado pela escrita, sendo esta a condição para o domínio de conceitos que permitem ao sujeito compreendê-lo e nele agir (FONTANA; CRUZ, 1997). A pessoa descobre a palavra e vai percebendo a linguagem como um processo dinâmico, pleno de múltiplos sentidos e significados.

Fialho (2012) e Carvalho (2002) indicam que para despertar o interesse do aluno à aprendizagem, se torna necessário utilizar uma linguagem atraente, aproximando-a ao máximo da realidade do aprendiz. Para o autor, atividades lúdicas contribuem no processo de ensino e aprendizagem, na elaboração de conceitos, na criatividade, no senso de cooperação e competição, dentre outros aspectos. Destaca-se a importância de o processo de ensino de leitura ser estimulante e oferecer oportunidades de exercícios reais de busca de conhecimento (BRASIL, 2007).

Logo, torna-se necessário que a criança tente, crie, construa e reconstrua hipóteses para se apropriar e usar significativamente a escrita como sistema simbólico. Para tal, a escrita 
precisa ser ensinada naturalmente e ser descoberta em situações de brincadeira, construindo um modo de linguagem e não apenas a escrita de letras (VIGOTSKI, 1998). Rego (2000) e Maluf (2008) defendem que o brincar auxilia a pessoa a desenvolver competências, aumentando, assim, o aprendizado, além de permitir que ela supere seus limites, suas dificuldades e interaja mais nos círculos sociais em que está inserida, contribuindo positivamente para sua autoestima.

Neste sentido, destaca-se que o brincar, de acordo com Brougère (1998), é um meio de inserção cultural, apropriação e criação da cultura lúdica infantil e que esta cultura é composta de certo número de esquemas que permitem iniciar a brincadeira, uma vez que se trata de produzir uma realidade diferente daquela da vida cotidiana: os verbos no imperfeito, os quadrinhos e os gestos estereotipados do início das brincadeiras compõem o vocabulário, cuja aquisição é indispensável.

Destaca-se que a cultura lúdica compreende, evidentemente, estruturas que também englobam os jogos com regras. $\mathrm{O}$ fato de se tratar de jogos tradicionais ou de jogos recentes não interfere na questão, mas é preciso saber que a cultura das regras se individualiza e se particulariza. A cultura lúdica não é um bloco monolítico, mas um conjunto vivo e diversificado, conforme os indivíduos e os grupos, em função dos hábitos lúdicos, das condições climáticas ou espaciais. Logo, a cultura lúdica se apodera de elementos da cultura do ambiente da criança para aclimatá-la ao jogo (BROUGÈRE, 1998).

Nesse sentido, Carvalho (2002), Conceição e Bomtempo (2014) e Tezani (2006) ressaltam que o jogar pode ser descrito como um fator protetivo às situações de vulnerabilidade social pois proporciona, em sua essência, alguns dos mecanismos que favorecem a resiliência de crianças contra processos invasivos.

Sabendo que a exposição aos fatores de risco pode afetar negativamente o desenvolvimento da criança/adolescente, motivando, dentre outras coisas, dificuldades acadêmicas, ressalta-se que a vivência de situações de baixo rendimento escolar pode gerar baixa autoestima e influenciar na capacidade produtiva da criança, prejudicando sua aprendizagem (MAZER; BELLO; BAZON, 2009).

Entendendo tais consequências relacionadas à situação de baixo rendimento escolar, Silva (2009) destaca que é importante que pesquisas busquem propostas de intervenção a serem realizadas pelas instituições de ensino a fim de oferecer suporte adequado para crianças expostas às situações de vulnerabilidade, buscando que tais crianças obtenham sucesso em seu rendimento nos primeiros anos de escolarização. 
A partir disso, destaca-se a necessidade de oferecer às crianças ferramentas que permitam a aquisição de habilidades e o desenvolvimento de crenças mais positivas em relação as suas próprias capacidades de realização (MEDEIROS et al., 2000; FERNANDES, 2016), visto que ações preventivas que envolvam as pessoas em situação de vulnerabilidade podem minimizar os fatores de risco, maximizando os fatores de proteção e tornando-as resilientes (SAPIENZA; PEDROMONICO, 2005).

Nesse contexto, para além da questão da resiliência, os jogos podem ser importantes para a promoção de mediação e aprendizagem, não só introduzindo atividades lúdicas e prazerosas, como também estimulando a concentração (FIALHO, 2012), uma vez que as atividades de leitura e de escrita, desenvolvidas por meio de jogos, além de constituírem uma boa proposta pedagógica, proporcionam, às crianças, a mediação (BRASIL, 2007). O jogo de tabuleiro ganha destaque por ser de conhecimento geral, podendo despertar facilmente o interesse pelas atividades propostas, à medida que estas respondam às necessidades históricosociais das pessoas (SILVA, 2011).

Diante disso, ressaltou-se o questionamento: O jogo de tabuleiro pode ser considerado um recurso no processo de apropriação de leitura e escrita? No que tange a teses e dissertações destaca-se que no período de 2006 a 2018 apenas seis trabalhos com a temática foram encontrados nos programas de educação (SILVA, 2009; RODRIGUES, 2013; AZEVEDO, 2016), nos de psicologia (SANTOS, 2012) e no programa de educação especial (SILVA, 2006; MURATA, 2013).

Nesse sentido, a presente pesquisa de abordagem qualitativa, caracterizada como pesquisa participante, se valeu dos procedimentos de observação, entrevista e avaliação pedagógica. Contou com três etapas: 1. Sondagem inicial; 2. Intervenção com jogos de tabuleiro; 3. Finalização. A seguir, apresenta-se o percurso metodológico adotado.

\section{Método}

Este estudo parte da compreensão que há dois tipos de desenvolvimento: i) o desenvolvimento real, ou seja, aquele revelado pelas instâncias em que a criança manifesta seus conhecimentos já internalizados e ii) o desenvolvimento potencial, o qual é configurado pelo saber que a criança não é capaz de manifestar autonomamente, mas que através de pistas do contexto e mediação do outro é capaz de realizar (VIGOTSKI, 1998).

A presente pesquisa parte da abordagem teórica que a mediação tem papel fundamental no desenvolvimento da mente, pois é a partir das relações sociais entre diferentes 
sujeitos que se estabelecem os processos de aprendizagem e, por consequência, o aprimoramento de suas estruturas mentais existentes desde o nascimento.

\begin{abstract}
A história do desenvolvimento das funções psicológicas superiores seria impossível sem um estudo de sua pré-história, de suas raízes biológicas, e de seu arranjo orgânico. As raízes do desenvolvimento de duas formas fundamentais, culturais, de comportamento, surge durante a infância: o uso de instrumentos e a fala humana. Isso, por si só coloca a infância no centro da pré-história e do desenvolvimento cultural (VIGOTSKI, 1998, p. 61).
\end{abstract}

Destaca-se que o conhecimento não está no sujeito nem no objeto, mas na relação entre ambos. Agindo sobre os objetos e sofrendo a ação destes, o homem amplia sua capacidade de conhecer, ou seja, de vivenciar processos de aprendizagem (VIGOTSKI, 1998).

Em relação à abordagem metodológica, esta pesquisa fundamenta-se na abordagem qualitativa, do tipo pesquisa participante. Os estudos com caráter qualitativo, em geral, são utilizados para descobrir e refinar as questões de pesquisa; além disso, buscam compreender o fenômeno de estudo em seu ambiente usual (aquele no qual as pessoas vivem, se comportam e atuam; e no qual pensam e agem). Nos estudos qualitativos podem ser desenvolvidas questões e hipóteses antes, durante ou depois da coleta de análise dos dados.

A pesquisa participante, segundo Brandão (2007), trata-se de um método de trabalho na educação popular realizado junto com o serviço das comunidades, grupos e movimentos sociais, em geral, populares. Sendo que a pesquisa participativa aspira a envolver-se em processos mais amplos e contínuos de construção progressiva de um saber mais partilhado, mais abrangente e mais sensível às origens do conhecimento popular.

Brandão (2007) afirma que a pesquisa participante se caracteriza por um tipo de investigação que a educação e a ação social convertem em momentos metodológicos de um único processo dirigido à transformação social. Deste modo, os sujeitos são estimulados a participar da pesquisa como protagonistas, isto é, como agentes ativos construindo o conhecimento e intervindo na realidade social.

\title{
Local
}

A pesquisa desenvolveu-se em aulas destinadas à oficina de Linguagem em uma Organização da Sociedade Civil (OSC) do interior do estado de São Paulo que tem suas atividades direcionadas ao atendimento de crianças e adolescentes do sexo feminino, de 6 a 17 anos, em contraturno escolar, priorizando famílias de baixa renda em que predominam mulheres como provedoras (mulheres 'chefes de família' sejam mães, avós, tias ou 
responsáveis legalmente), residentes na região periférica da cidade de Araraquara. A missão da OSC, aqui denominada Organização Civil, é contribuir para o desenvolvimento integral de crianças e adolescentes, por meio da participação e convivência em espaços e atividades culturais, educacionais e sociais - complementares à família, à escola e à comunidade. A pesquisa foi desenvolvida em uma sala disponibilizada pela instituição, no horário em que elas estariam na oficina de linguagem.

\section{Participantes}

A seleção das participantes se deu por meio de entrevista com a educadora da Oficina de Linguagem e avaliação inicial de repertório de alfabetização. Participaram deste estudo 14 meninas de 7 a 10 anos de idade que frequentavam a organização civil e apresentavam dificuldades de aprendizagem, sendo: duas participantes de 7 anos que frequentavam o primeiro ano do ensino fundamental, nove de 8 anos matriculadas no terceiro ano do ensino fundamental e três de 9 anos que frequentavam o quarto ano do ensino fundamental.

Após o momento de sondagem inicial as quatorze meninas foram organizadas em quatro grupos, conforme seus conhecimentos prévios sobre leitura e escrita e também de acordo com as afinidades que foram observadas durante as intervenções iniciais e relatadas pela educadora na entrevista. Tal proposta se deu na certeza de que as interações sociais são formas de construção de saberes e aprendizado de regras do jogo e não resultam apenas em engajamento individual na solução de problemas (BRANDÃO, 2007).

Também foi realizada uma entrevista semiestruturada com a educadora responsável pela Oficina de Linguagem, com o objetivo de realizar sondagem do conhecimento prévio e das potencialidades das meninas participantes. A educadora entrevistada, aqui denominada de Manoela (nome fictício), era formada há dez anos em Letras pela Universidade Estadual Paulista Júlio de Mesquita Filho - UNESP e trabalhava há um ano na organização civil.

\section{Procedimentos de coleta e análise dos dados}

Cabe esclarecer que o projeto da pesquisa foi apresentado ao 'Comitê de Ética' e, após aprovado (CAEE: 64352917700005504), os participantes e/ou seus responsáveis assinaram o 'Termo de Consentimento Livre e Esclarecido', que descreve as informações deste estudo e firma o compromisso ético. 


\section{Instrumentos}

Destaca-se que o presente estudo foi dividido em três etapas: sondagem inicial, intervenção/aplicação dos jogos e finalização. Na primeira etapa foi investigado por meio de atividades e diálogos coletivos, conforme mencionado, o conhecimento prévio, as potencialidades e os interesses das participantes. Para esta sondagem utilizou-se um roteiro semiestruturado de entrevista com a educadora responsável pela 'Oficina de Linguagem' e o IAR (Instrumento de avaliação do repertório básico para a alfabetização), para avaliação pedagógica inicial, que verificou: esquema corporal; lateralidade; posição; direção; espaço; tamanho; quantidade; forma; discriminação visual; discriminação auditiva; verbalização de palavras; análise-síntese e coordenação motora.

$\mathrm{Na}$ segunda etapa de intervenção, realizou-se a aplicação de dois jogos de tabuleiro. Em ambas as etapas se optou pela observação participante como forma de coleta de dados. $\mathrm{Na}$ terceira e última etapa, realizou-se a sondagem somativa, com (re)aplicação de instrumento de avaliação pedagógica.

\section{Análise de dados}

A análise dos dados foi realizada baseando-se principalmente nos trabalhos de Lüdke e André (1986) e Brandão (2007) e foram utilizados os instrumentos de observação/avaliação e entrevista previstos para os estudos educacionais que focalizam projetos de ação. No registro das observações realizadas procurou-se combinar anotações escritas com fotos.

Os resultados dos instrumentos de entrevista e observação, análise das avaliações pedagógicas e os depoimentos das participantes deste trabalho foram destacados no texto e apresentados com nomes fíctícios. No que se refere à observação realizada foram considerados os comportamentos notados, os dados da entrevista e os resultados das avaliações pedagógicas.

O conteúdo das observações, seguindo orientações de Lüdke e André (1986) e com adaptação do trabalho de Zeppone (1999), contém registros das observações realizadas sobre os comportamentos das participantes, eventos especiais e de atividades e/ou uma reconstrução de diálogos. A partir de cada parte descritiva, pretendeu-se realizar uma análise reflexiva dos registros.

Por meio dos encontros em que participantes se envolveram ativamente e partindo dos conhecimentos prévios quanto à leitura e escrita, procurou-se, através do jogo de tabuleiro, ampliar essas habilidades. 
As entrevistas foram transcritas e analisadas, seus elementos foram classificados por suas características semelhantes e não semelhantes, e posteriormente foram organizados em função de características comuns. Foram analisados os registros feitos pelos participantes (tarefas ao decorrer do jogo) e as informações coletadas por meio das observações que foram organizadas, analisadas e descritas, a fim de identificar os pontos relevantes referentes às principais características dos participantes (GIL, 2008).

\section{Resultados}

O presente trabalho partiu da premissa de que vivemos em um mundo orientado pela escrita (FONTANA; CRUZ, 1997) no qual o brincar lúdico auxilia a criança a desenvolver competências (FIALHO, 2012), sua capacidade de aprendizagem (MALUF, 2008), bem como a ajuda a superar os seus limites (CONCEIÇÃO; BONTEMPO, 2014). Nesse sentido a pesquisa utilizou o jogo de tabuleiro como ferramenta pedagógica para ensino de habilidades de leitura e escrita de crianças em situações de vulnerabilidade social, que apresentavam dificuldades de aprendizagem.

\section{Entre desafios e resistências}

No que se refere à entrevista com a educadora social da oficina de linguagem na etapa de sondagem, em seu discurso muitas vezes argumentou: "na faculdade não aprendi a alfabetizar e percebo que tenho muita dificuldade com isso". A educadora apresenta outras falas sobre a formação: "as matérias de licenciatura são poucas, tive mais preparo acadêmico para pesquisa em língua e escrita do que para o ensino destas".

Segundo Soares (1992), há defasagem nos cursos de formação docente, um exemplo disso é a falta de materiais de leitura que façam os(as) alunos(as) imergir em um ambiente de letramento e prática deste.

Ressalta-se que dificuldades estavam presentes na rotina de aprendizagem das meninas dentro da oficina de linguagem, segundo a fala da educadora entrevistada: "Elas resistem muito em atividades novas, apresentando mau comportamento". "Apresentam muitas vezes resistência a atividades que exijam concentração". "De maneira geral todas as crianças reagem com sigilo em situações novas, apresentando comportamento de fuga elou mau comportamento ao se depararem com ambientes e situações inusitadas mais complexas". 
Nesse sentido, Santos (2012) aponta que problemas emocionais e/ou de comportamento geram, muitas vezes, fuga de atividades que apresentam complexidade. Quando esses fatores estiverem fortemente associados a fatores de risco no ambiente escolar e social, podem afetar negativamente o desenvolvimento.

\section{Para além da dificuldade e vulnerabilidade: sujeitos de interesse}

No que concerne aos resultados da pesquisa em relação às crianças, esses demonstraram que, durante a sondagem (observação), as participantes que apresentavam dúvidas muitas vezes mostravam-se resistentes frente às atividades que envolviam leitura e escrita por se considerarem incapazes de realizá-las; nesse sentido, Mazer, Bello e Bazon (2009), destacam que a vivência de situações de baixo rendimento escolar, muitas vezes gerado por situações de vulnerabilidade, pode resultar em baixa autoestima e também influenciar na capacidade produtiva do indivíduo, prejudicando sua aprendizagem.

Outra questão observada foi a baixa autoeficácia na realização das atividades, à medida que se consideravam incapazes de fazê-la, alguns dos relatos foram: "Gostei, mas fui mal” (Alice). “Achei bonito o jogo, mas sou ruim" (Helena). "Sou ruim”. (Jasmine). Tal dado entra em concordância com os estudantes observados por Silva (2009) que se consideravam os únicos culpados por seu 'fracasso' escolar.

Durante as sessões de levantamento de interesse para a elaboração dos jogos, observou-se que as crianças possuíam gostos semelhantes, possivelmente por pertencerem a um contexto histórico-cultural próximo, demonstrando afeição por personagens de longa metragem infantil, muitas vezes até por encontrem semelhanças psicológicas e físicas com estes. Tavares (2016) ressalta que a apreciação fílmica como provocação estética de um olhar que se volta para si mesmo pode possibilitar a construção de relações dialógicas problematizadoras que põe em evidência valores que se tencionam na relação com o outro e consigo mesmo.

Destaca-se que, segundo Amaral e Monteiro (2016), a linguagem cinematográfica se configura hoje como uma das principais disseminadoras de comportamentos e representações culturais, sendo os filmes infantis grandes ferramentas auxiliadoras no processo de formação da identidade infantil (POLETTO; PIASSI, 2011). 


\section{O jogo como centralidade do processo de aprendizagem}

Nas sessões de construção do tabuleiro, através do uso do computador e internet (escolhas de imagens) as crianças se mostraram envolvidas. Durante o processo observou-se o envolvimento das crianças com as atividades concernentes ao jogo de tabuleiro e o empenho destas na realização das atividades, apesar de suas fragilidades e dificuldades, conforme dito por Fialho (2012).

Para jogar o jogo, a criança, primeiramente, lança o dado. O número presente no dado corresponde a uma tarefa presente na ficha elaborada pela pesquisadora. Durante os dois jogos, as crianças precisaram realizar as tarefas de maneira a respeitar as regras e interagir com o restante do grupo, sendo permitido ajuda mútua para que todas conseguissem acertar as atividades propostas, muitas vezes sendo mediadas pela pesquisadora. A criança poderia andar para a próxima casa mesmo se não acertasse a palavra na primeira tentativa.

Ressalta-se que as tarefas presentes nas fichas trabalharam as habilidades avaliadas através da aplicação do IAR, que segundo Leite (2015), tem como vantagem planejar menos em função de sua subjetividade e mais em função da realidade do aluno.

No primeiro jogo foram trabalhadas as habilidades pré-alfabéticas e no segundo as habilidades alfabéticas (como construção de sílabas, palavras e frases).

\section{Descrição das sessões}

Durante as sessões de intervenção com o jogo, observou-se a importância da mediação nesse processo que se deu por meio de perguntas como: "O que tem no castelo?"; "Quais palavras podemos escrever?"; "Pode ser pequenininha?". Ressalta-se que o conhecimento não está na participante nem no objeto geométrico utilizado, mas na relação entre ambos. Para Fernandez (2016), agindo sobre os objetos e sofrendo a ação destes, o homem amplia a sua capacidade de conhecer, ou seja, de vivenciar processos de aprendizagem.

Ressalta-se aqui a troca de aprendizados entre as participantes com as seguintes verbalizações: "Nossa! Que bom que a Alice está no grupo ela é boa com os tijolos" (Laura). “Obrigada, você me ajudou! Desculpa ter batido em você ontem”. (Jasmine). Tais dados nos indicam que no processo de aprendizagem o ser humano necessita estabelecer uma rede de contatos com outros seres humanos para incrementar e construir novos conceitos (VIGOTSKI, 1998) e que a educação tem caráter permanente, isto é, não há seres educados e não-educados, estamos todos em processo (RAPOPORT, 2009). 
O trabalho conjunto das meninas colaborou com a união e organização do grupo, muitas vezes as participantes pediam ajuda umas para as outras: "Vou precisar de uma ajudinha aqui" (Ariel). Percebemos, assim, a importância da aprendizagem com os próprios colegas mais capazes, quando uma criança exprime suas dificuldades para compreender, não se limitando apenas ao professor, mas sim a todos os integrantes do grupo a tarefa de colaborar para que a aprendizagem ocorra (TEZANI, 2006).

Ressalta-se que durante o processo das atividades de escrita, algumas das palavras não possuíam real significado, mas representavam naquele momento um 'brincar com letras' Nesse sentido, Vigotski (1998) afirma que a criança, em sua alfabetização, traça inicialmente palavras e letras por mera imitação externa, não havendo ainda compreensão de seu significado, dado que é ao passo da ação do outro que vai se apropriando dos conhecimentos do mundo e começa a descobrir aspectos novos do universo.

A partir disso, destaca-se a necessidade de oferecer às crianças ferramentas que permitam a aquisição de habilidades e o desenvolvimento de crenças mais positivas em relação às suas próprias habilidades de realização (MEDEIROS et al., 2000).

Após o término dos jogos, a pesquisadora usou uma sessão com cada grupo destinada à roda de conversa e música. Em mais um momento de interação, conversou sobre as sessões e as participantes deram suas opiniões: "O que mais gostei é que vim brincar aí depois vi que aprender não é ruim" (Laura); "Leva esse jogo na escola, Dona, aí paro de faltar" (Gamora); "Foi bem legal, principalmente o da Moana, estava mais colorido" (Merida); "Eu gostei, porque sempre dava risada" (Alice); "Nem vi que estava escrevendo, foi engraçado" (Luna); "Eu fui boa no jogo" (Mala); "Não quis fugir da sala, porque estava legal” (Ariel).

Destaca-se a maneira que falaram do jogo como engraçado, colorido, oralizando o que aprenderam. Tais dados indicam a importância sobre o uso do jogo como ferramenta pedagógica e para os processos de aprendizagem e desenvolvimento, abrangendo as aprendizagens já consolidadas e sendo um recurso de mediação para aprendizagens que ainda vão se consolidar (TEZANI, 2006).

\section{O jogo como instrumento pedagógico}

Os resultados das avaliações diagnósticas e somativas mostraram um ganho de habilidades no processo de aquisição de leitura e escrita: a aplicação do IAR (Instrumento de Avaliação do repertório básico para a alfabetização) demonstrou que todas as meninas ganharam habilidades novas possivelmente por influência do jogo. 
Figura 1 - IAR: roteiro de resposta Inicial

\begin{tabular}{|c|c|c|c|c|c|c|c|c|c|c|c|c|c|}
\hline Nomes & $\begin{array}{l}\text { Esq. } \\
\text { Corporal }\end{array}$ & Lateralidade & Posicão & Direcão & Espaco & Tamanho & Quantidade & Forma & $\begin{array}{l}\text { Disc. } \\
\text { Visual } \\
\end{array}$ & $\begin{array}{l}\text { Disc. } \\
\text { Auditiva }\end{array}$ & \begin{tabular}{|l} 
Ver. \\
Palavras \\
\end{tabular} & Sintese & $\begin{array}{l}\text { Mota } \\
\text { Fina }\end{array}$ \\
\hline \multicolumn{14}{|l|}{ Arie1 } \\
\hline \multicolumn{14}{|l|}{ Merida } \\
\hline \multicolumn{14}{|l|}{ Luna. } \\
\hline \multicolumn{14}{|l|}{ Diana } \\
\hline \multicolumn{14}{|l|}{ E1za } \\
\hline \multicolumn{14}{|l|}{ Helena } \\
\hline \multicolumn{14}{|l|}{ Gamora } \\
\hline \multicolumn{14}{|l|}{ Fiona } \\
\hline \multicolumn{14}{|l|}{ Nala } \\
\hline \multicolumn{14}{|l|}{ Alice } \\
\hline \multicolumn{14}{|l|}{ Laura } \\
\hline \multicolumn{14}{|l|}{ Isabel } \\
\hline \multicolumn{14}{|l|}{ Jasmine } \\
\hline Rapunze1 & & & & & & & & & & & & & \\
\hline
\end{tabular}

\begin{tabular}{|c|c|}
\hline Legenda & Acertos \\
\hline & $100 \%$ \\
\hline & + ou $=50 \%$ \\
\hline & $-50 \%$ \\
\hline
\end{tabular}

Fonte: Elaborado pelas autoras

Figura 2 - IAR: roteiro de resposta final

\begin{tabular}{|c|l|l|l|l|l|l|l|l|l|l|l|l|l|}
\hline Nomes & $\begin{array}{l}\text { Fsq. } \\
\text { Corporal }\end{array}$ & Lateralidade & Posicão & Direcão & Espaco & Tamanho & Ouantidade & Forma & $\begin{array}{l}\text { Disc. } \\
\text { Visual }\end{array}$ & $\begin{array}{l}\text { Disc. } \\
\text { Auditiva }\end{array}$ & $\begin{array}{l}\text { Ver. } \\
\text { Palavas }\end{array}$ & Sintese & $\begin{array}{l}\text { Mota } \\
\text { Fina }\end{array}$ \\
\hline Ariel & & & & & & & & & & & & & \\
\hline Merida & & & & & & & & & & & & & \\
\hline Luna & & & & & & & & & & & & & \\
\hline Diana & & & & & & & & & & & & \\
\hline Elza & & & & & & & & & & & & & \\
\hline Helena & & & & & & & & & & & & & \\
\hline Gamora & & & & & & & & & & & & \\
\hline Fiona & & & & & & & & & & & & & \\
\hline Nala & & & & & & & & & & & & & \\
\hline Alice & & & & & & & & & & & & & \\
\hline Laura & & & & & & & & & & & & & \\
\hline Isabel & & & & & & & & & & & & & \\
\hline Jasmine & & & & & & & & & & & & & \\
\hline Rapunzel & & & & & & & & & & & & & \\
\hline
\end{tabular}

\begin{tabular}{|c|c|}
\hline Legenda & Acertos \\
\hline & $100 \%$ \\
\hline & $+\mathrm{ou}=50 \%$ \\
\hline & $-50 \%$ \\
\hline
\end{tabular}

Fonte: Elaborado pelas autoras

A partir dos resultados obtidos verificou-se que foi proporcionado um espaço potencial de aprendizagem, espaço lúdico, relaxado, que apresentou informações às quais o educando estivesse pronto para recriar, apropriando-se de conteúdos relevantes de forma criativa, singular, segundo suas concepções e necessidades (TEZANI, 2006). 
É importante analisar o aspecto cognitivo do uso dos jogos como ferramenta pedagógica e sua importância para os processos de aprendizagem e desenvolvimento (TEZANI, 2006). Certamente não foi apenas por meio dos jogos que as crianças desenvolveram as habilidades de leitura e escrita, no entanto, nota-se que o uso dos jogos tornou prazeroso o aprender, enfatizando além do cognitivo o aspecto afetivo da aprendizagem (REGO, 2000).

\section{Considerações finais}

As teses e dissertações encontradas sobre a temática trouxeram em suas considerações a espera por pesquisas futuras, Silva (2006), Silva (2009) e Marata (2013) para a importância de trabalhos de identificação do chamado 'fracasso escolar' e estudos que ofereçam meios de intervir sobre o processo de ensino e aprendizagem em escolas que atendam alunos expostos a fatores de risco. Santos (2012) ressalta que existem lacunas a serem preenchidas em espaços escolares, logo, identifica-se a necessidade de mais estudos que tenham como foco a atenção à criança em vulnerabilidade, em suas necessidades de estimulação, visando-se a superação de problemas gerados pela exposição a fatores de risco, maximizando seus recursos internos de enfrentamento e criando fatores de proteção que lhes forneçam continência apropriada diante das dificuldades.

Destaca-se que a pesquisa de levantamento bibliográfico de Mazer et. al. (2009) constatou que futuras pesquisas precisam não apenas compreender como os processos de aprendizagem e desenvolvimento podem ser afetados por estas condições, mas também, buscar propostas de intervenção a serem realizadas pelas instituições de ensino e de apoio em prol do desenvolvimento dos seus alunos.

A partir disso, percebe-se a importância do presente estudo que buscou utilizar o jogo como uma ferramenta pedagógica para alfabetização de crianças com dificuldade de aprendizagem.

Compreendendo a importância da mediação e fazendo uso de um jogo lúdico de tabuleiro como ferramenta pedagógica de aprendizado, este trabalho buscou ensinar habilidades de leitura e escrita para crianças em situações de vulnerabilidade social, que apresentavam dificuldades de aprendizagem.

Observou-se o trabalho em equipe e o processo de ensino e aprendizagem de maneira mediada, visto que pediram ajuda uns aos outros e à pesquisadora. Ressalta-se que as participantes aprendiam sem constrangimento e não se sentiam incapazes com as dificuldades. 
Nesse sentido, Carvalho (2002) ressalta a importância de uma efetiva mediação dentro do processo de ensino e aprendizagem de leitura e escrita, sendo cada aprendiz único, cabendo ao educador buscar ferramentas de mediação para essa aprendizagem.

Os resultados mostraram um ganho de habilidades ao processo de aquisição de leitura e escrita, as participantes ganharam habilidades novas, houve um avanço das participantes no processo de simbologia da escrita, visto que foi percebido que as crianças não alfabetizadas na avaliação pedagógica somativa já apresentavam o desenho de letras para a escrita das palavras ditadas, entendendo que estas fazem parte do acordo sócio-cultural da escrita; Vigotski (1980) relata que, nesse processo, as letras e palavras tornam-se símbolos interpretáveis e funcionais nos seus registros, consequentemente a criança descobre a palavra e vai percebendo a linguagem como um processo dinâmico repleto de múltiplos sentidos e significados

Durante as sessões de coleta de dados, observou-se o envolvimento das crianças com as atividades concernentes ao jogo de tabuleiro, sendo destacado o caráter motivacional dos jogos. Os resultados das avaliações mostraram um ganho de habilidades ao processo de aquisição de leitura e escrita, e a aplicação do IAR demonstrou que todas as meninas ganharam habilidades novas, possivelmente por influência do jogo.

Logo, o uso de jogos de tabuleiro como uma ferramenta pedagógica no processo de aquisição da leitura e escrita de crianças com dificuldade de aprendizado em situação de vulnerabilidade social, matriculadas no ensino regular, parece favorecer o ganho em habilidades que favorecem a apropriação da leitura e escrita, sendo um meio facilitador e motivador no processo de ensino e aprendizagem.

A partir dos resultados alcançados nesta pesquisa se destaca a importância do desenvolvimento de novos estudos que ofereçam diferentes mecanismos de ensino das habilidades de leitura e escrita, com foco nas potencialidades e saberes do aprendiz, para que esse de fato torne-se ativo no processo de ensino e aprendizagem.

AGRADECIMENTOS: Ao CNPq que financiou minha pesquisa.

\section{REFERÊNCIAS}

AMARAL, M. H; MONTEIRO, M. I. B. Análise de Obras Cinematográficas para Compreender as Concepções de Professores sobre o Aluno com Deficiência. Revista Brasileira de Educação Especial, v. 22, n. 4, p. 511-526, 2016. 
AZEVEDO, F. Oração inaugural. In: BARREIRA, C. A sociologia no tempo: memória, imaginação e utopia. São Paulo: Cortez, 2006.

BEE, H. O ciclo vital. Porto Alegre: Artmed, 1997.

BRANDÃO, G, M. Linhagens do pensamento político brasileiro. São Paulo: Aderaldo \& Rothschild Editores, 2007.

BROUGÈRE, G. A criança e a cultura lúdica. Revista da Faculdade de Educação, v. 24, n. 2, 1998.

CARVALHO, M. Guia prático do alfabetizador. São Paulo: Ática, 2002.

CONCEICAO, M. R.; BOMTEMPO, E. Infância e Contextos de Vulnerabilidade Social: a atividade lúdica como recurso de intervenção nos cuidados em saúde. Boletim - Academia Paulista de Psicologia, v. 34, n. 21, p. 490-509, 2014.

FERNANDES, O. O Pacto Nacional pela Alfabetização na Idade Certa e o Uso de Jogos na Aprendizagem Inicial da Leitura e Escrita. Educação em revista, v. 17, n. 2, p. 15-35, 2016.

FERREIRA, M.; MARTURANO, E. M. Ambiente familiar e os problemas do comportamento apresentados por crianças com baixo desempenho escolar. Psicologia:

Reflexão e Critica, v. 15, n. 1, p. 35-44, 2002.

FIALHO, N. Os jogos pedagógicos como ferramentas de ensino. Curitiba: IBPEX, 2012.

FONTANA, R.; CRUZ, M. N. Psicologia e trabalho pedagógico. São Paulo: Atual, 1997.

GIL, A. C. Como elaborar projetos de pesquisa. 4. ed. São Paulo: Atlas, 2008.

LEITE, S. A. S. Instrumento de avaliação do repertório básico para alfabetização: manual de aplicação e avaliação. 3. ed. São Paulo: EDICON, 2015.

LÜDKE, M.; ANDRÉ, M. E. D. Pesquisa em educação: abordagens qualitativas. São Paulo: EPU, 1986.

MALUF, A. C. M. Atividades recreativas para divertir e ensinar. 4. ed. Petrópolis: Vozes, 2008.

MAZER, S. M.; BELLO, A. C. D.; BAZON, M. R. Dificuldades de aprendizagem: revisão de literatura sobre os fatores de risco associados. Revista Psicologia da Educação, v. 10, n. 28, p. 7-21, 2009.

MEDEIROS, P.C. et al. A auto eficácia e os aspectos comportamentais de crianças com dificuldade de aprendizagem. Psicologia: Reflexão e Crítica, v. 13, n. 3, p. 327-336, 2000.

POLETTO, A. PIASSI, L. P. O cinema e os filmes infantis na inserção de valores: o uso do filme como treinar o seu dragão na exploração do tema diversidade e preconceito. In: CONGRESSO BRASILEIRO DE CIÊNCIAS DA COMUNICAÇÃO, 34., 2011, Recife. Anais [...]. Recife: Intercom, 2011. 
RAPOPORT, A.; SARMENTO, D. F. Desenvolvimento e aprendizagem infantil: implicações no contexto do primeiro ano a partir da perspectiva Vygotskiana. In: RAPOPORT, A. et al. (org.). A Criança de seis anos no Ensino Fundamental. Porto Alegre: Mediação, 2009.

REGO, T. C. Vygotsky: uma perspectiva histórico-cultural da educação. 10. ed. Petrópolis: Vozes, 2000.

SANTOS, C. P. 'Ele é multifacetado': as representações sociais do fracasso escolar construídas e compartilhadas por psicólogos educacionais. 2012. 150 f. Dissertação (Mestrado em Psicologia) - Centro de Filosofia e Ciências Humanas, Universidade Federal de Pernambuco, Recife, 2012.

SANTOS, L. C.; MARTURANO, E. M. Crianças com dificuldade de aprendizagem: um estudo de seguimento. Psicologia: Reflexão e Crítica, v. 12, n. 2, p. 377-394, 1999.

SAPIENZA, G.; PEDROMÔNICO, M. R. M. Risco, proteção e resiliência no desenvolvimento da criança e do adolescente. Psicologia em Estudo, v. 10, n. 16, p. 209-216, 2005 .

SILVA, A. P. F. Reprovados, indisciplinados, fracassados: as micro-relações de insucesso escolar na perspectiva do 'aluno problema'. 2009. 446 f. Tese (Doutorado em Educação) Pontifícia Universidade Católica de São Paulo, São Paulo, 2009.

SOARES, M. Linguagem e escola: uma perspectiva social. 9. ed. São Paulo: Ática, 1992.

SOUZA, S. R.; HÜBNER, M. Efeitos de um jogo de tabuleiro educativo na aquisição de leitura e escrita. Acta Comportamentalia, v. 18, n. 2, p. 215-242, 2010.

TAVARES, S. F. Cinema e pessoa com deficiência: a (re)significação do olhar de professoras. 2016. 100 f. Dissertação (Mestrado em Educação) - Universidade Federal do Rio Grande do Norte, Natal, 2016.

TEZANI, T. C. Rodrigues. O jogo e os processos de aprendizagem e desenvolvimento: aspectos cognitivos e afetivos. Educação em Revista, v. 7, n. 1/2, p. 1-16, 2006.

VIGOSTSKI, L. S. Formação social da mente. São Paulo: Martins Fontes, 1998.

ZEPPONE, R. M. O. Educação ambiental: teorias e práticas escolares. 1. ed. São Paulo. Jm, 1999. 


\section{Como referenciar este artigo}

VASCONCELLOS, T. S. P.; ORLANDO, R. M. Jogos de tabuleiro: recurso lúdico na aprendizagem de crianças em situação de vulnerabilidade. Revista Ibero-Americana de Estudos em Educação, Araraquara, v. 16, n. 4, p. 2630-2647, out./dez. 2021. e-ISSN: 19825587. DOI: https://doi.org/10.21723/riaee.v16i4.13660

Submetido em: 15/07/2021

Revisões requeridas em: 09/08/2021

Aprovado em: 11/09/2021

Publicado em: 21/10/2021 